\title{
EL DERECHO DE SUCESIÓN EN LA ELECTRA DE SÓFOCLES
}

\author{
MARÍA del CARMEN CABRERO
}

\begin{abstract}
This paper tries to focus Sophocle's Electra from a point of view interested on early legal aspects, that were sketched around the big theme of revenge. All this belongs to the social and cultural frame in which the legislation of the Greek people originated and developed. In order to achieve this study, the authoress makes a review of the mention in the prologue of enthronizing rites that, added to the commandement of the Apolo's oracle, would permit Orestes to assume the function of Delphic god when he proclaims himself as $\kappa \alpha \theta \alpha \rho \tau$ ' $s$.
\end{abstract}

\section{Presentación del tema}

Como toda obra clásica, la Electra de Sófocles ha sido objeto, desde su primera representación, en los festivales dionisíacos de Atenas, de numerosas y entusiastas interpretaciones que avalan cualquier intento de reencuentro con ella. Por eso deseamos abordarla desde una lectura interesada por los aspectos jurídicos del prederecho, que se esbozan en ella como parte de un marco social y cultural en el que nació y se desarrolló la legislación del pueblo griego. Intentaremos acercarnos al gran tema de la venganza desde dos aspectos: la sociedad y la religión. Al recuperar los rasgos más destacados de ambas manifestaciones en su encuentro con algunos de los procedimientos legales áticos, será posible advertir cómo Sófocles los ha adaptado como marco de la acción, orientándolos por un camino comprensible para su audiencia, familiarizada ya con el aparato judicial de la ciudad.

El prólogo nos enfrenta, en primer lugar, con el pedagogo, Orestes y Pílades que han regresado secretamente y contemplan la región de Argos. Es el pedagogo el encargado de abrir el prólogo presentando al hijo de Agamenón como heredero y 
sucesor (v.1-22). En relación con su filiación, enfatiza su misión de vengador del asesinato de su padre y le recuerda que ha llegado la ocasión de pasar a la

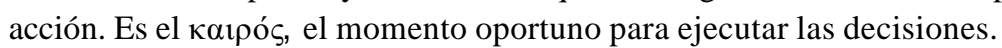

Orestes toma la palabra en segundo lugar, (v. 23-78) y tras alabar la fidelidad de su ayo informa acerca de su viaje a Delfos. Rememora las palabras del oráculo pítico que le profetizó que, después de coronar la tumba de su padre con bucles cortados de su cabellera y libaciones, podría ejecutar, «sin ejército y con ardides,

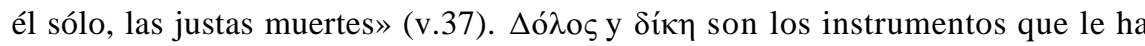

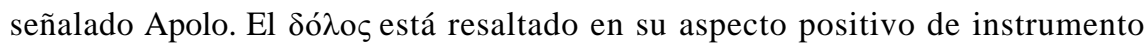
indispensable de la $\delta$ í $\eta$, e implica, para Orestes, su falsa muerte, a fin de que un muerto pueda vengar a otro muerto, que en cierto modo es su reencarnación. Expone con detalle el plan de venganza y la parte que le toca ejecutar a cada uno, exigiendo la adhesión de sus acompañantes para cumplir el oráculo. Eleva su plegaria a los dioses tutelares, a la tierra patria y al palacio paterno para que no lo rechacen deshonrado.

Al final del discurso de Orestes el espectador posee todos los datos que le permitirán seguir el curso de la acción, menos uno: el grado de juramentocompromiso de Electra. La hermana, que actuó heroicamente para salvar al hermano varón, ha sido mencionada por el pedagogo. Pero luego, en el dis-

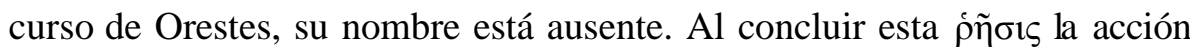

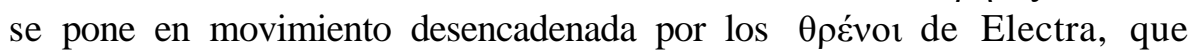
adquiere desde este momento un protagonismo que le era ajeno en los dramas de Esquilo y Eurípides. Con ello tan sólo pretendemos observar uno de los tantos problemas que se desprenden de la asimilación de fuentes, pues no hay datos respecto a la cronología de la Electra de Sófocles y la de Eurípides, no hay didascalia ni escolios que revelen con seguridad cuál fue primera, sólo se observan las muchas semejanzas textuales que las acercan.

Es evidente que con Sófocles, por primera vez, Electra domina la escena totalmente desde el monólogo trenódico que cierra el prólogo hasta el final. El primer lamento de Electra se alcanza a oír desde donde se encuentran los recién llegados. Una duda por parte de Orestes es dominada por el pedagogo y abandonan la escena.

En este punto de la obra podemos ya elucidar algunos rasgos del rito de entronización que, sumados al mandato del oráculo de Apolo, permitirán a Orestes asumir la función propia del dios de Delfos al presentarse a

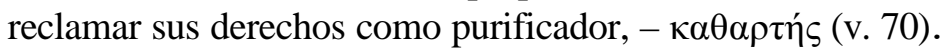


El primero de ellos nos muestra cómo se ponen de manifiesto las profundas motivaciones que permiten a Orestes, por un lado, formalizar su "petición para fundar su herencia" como un rito de $\dot{\varepsilon} \mu \beta \alpha ́ \tau \varepsilon v \sigma 1 \varsigma$ y su "acción

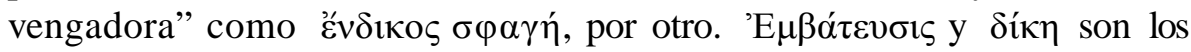
pasos previos de la venganza. El segundo, cómo esas motivaciones son acordes con una serie de componentes que actúan como configuradores del proceso judicial ateniense aún en el siglo $\mathrm{V}$.

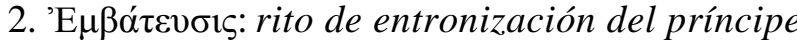

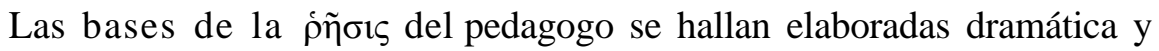

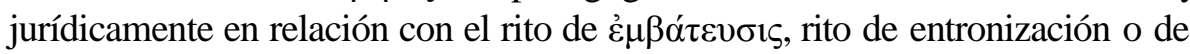
toma de posesión de una herencia. La sucesión se refería en un principio sólo a los hijos de reyes, sacerdotes o adivinos, y el acto que la probaba radicaba en el uso del patronímico con significado dinástico. El complemento natural de la investidura de un personaje noble es el acto de arrogarse una filiación y una jerarquía, a la vez que un nombre. Tal es el sentido que alcanza el patronímico que abre la exposición del ayo: «Oh hijo de Agamenón, el que en otro tiempo estuvo al frente del ejército en Troya!» (v.1-2). El príncipe de Micenas penetra en la tierra patria accediendo así a un espacio con significación y virtualidad religiosa, que era la base del rito de entronización, y lo hace a través del más alto rango alcanzado por su padre. La

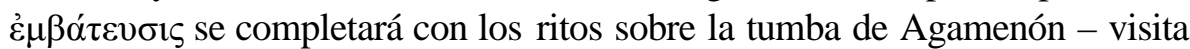
sólo mencionada en la $\hat{\rho} \tilde{\eta} \sigma ı$ de Orestes -, que redondea el procedimiento arcaico, de carácter mágico, que luego el derecho irá integrando en un cuadro más racional y sometido al control de una concepción más rigurosa de la ley.

Toda la tragedia de los Pelópidas podría leerse como un mito sucesorio, en el cual el regreso de Orestes, tras el exilio, lo lleva a penetrar en su anhelada Argólida, su patria, como el sucesor, el que está calificado para realizar actos eficaces. Sólo con tal carácter el acto de "toma de posesión" alcanza una fuerza propia. En este contexto es el hijo varón, exclusivamente, quien hereda el $\kappa \lambda \tilde{\eta} \rho \circ \varsigma$ paterno, patrimonio largo tiempo inalienable, que constituye como la sustancia visible de la familia. La tierra, bien familiar, estable y permanente, es la única que posee un estatuto de plena realidad y su precio se matiza con un valor afectivo y religioso. Es el hombre en el seno de esta sociedad masculina, el que simboliza los bienes raíces de la oĩкo $\varsigma$, estos $\pi \alpha \tau \rho \tilde{1} 1 \alpha$ que mantienen a lo largo de las generaciones la unión de un 
linaje con el terruño donde están establecidos. Penetrar en la tiera patria, luego del exilio, significa para Orestes penetrar en un ámbito cualificado, espacio del santuario mítico, donde la representación espacial resulta esencial. El Pedagogo se aboca, entonces, a describirle la Argólida. Parece contemplarla desde una de las colinas que constituyen sus límites naturales, la Profitis Ilias, al norte, o la Zara, al sur. Su mirada se detiene primero en ese espacio global ocupado principalmente por el monte Arachneon, donde se alza «la antigua Argos» - $\pi \alpha \lambda \alpha \iota o ́ v$ (v. 4). En el epíteto está contenida la rica historia de esta región, pues como lo muestran las viejas leyendas y como más tarde lo señalará Herodoto, es allí, en el Golfo Argivo donde nacieron y crecieron las relaciones entre Grecia y Asia. A continuación, le señala los principales ámbitos religiosos dando prioridad al ágora de Apolo, el más espléndido y temido de los dioses olímpicos, hijo de Zeus y su profeta: «la plaza licia del dios matador de lobos» (v.7). A la izquierda de su ágora, continúa diciéndole, se alza el «famoso templo de Hera» (v. 8), la esposa de Zeus. Su epíteto permanente es ,rgeía. Es la argiva kórh, diosa principal del Argos peloponesio en tiempos históricos. La mención del Heraion muestra la importancia que tenía su culto para la vida familiar, el matrimonio y la fertilidad. Y finalmente, el pedagogo focaliza los centros de la vida cívica: la ciudad de Micenas, «la rica en oro » (v. 9), presentada con uno de los epítetos homéricos más queridos para la ciudad, y en el centro de ella, el palacio de los Pelópidas, «lleno de horrores» (v. 10). La casa es lo que da al culto familiar sus fundamentos más definidos, tanto por estar concebida bajo una autoridad monárquica, como por la noción religiosa que la engloba. Constituye así el símbolo más abarcativo de este culto. De ahí que contemplar el palacio, por cuya puerta habrán de penetrar para vengar la memoria del rey Agamenón y recuperar la herencia, tenga para los recién llegados un eminente valor religioso.

Los cinco espacios elegidos se van visualizando en una gradación que lleva a Orestes a ponerse en contacto con las fuerzas que afloran de su o $\mu$ koj, las emanadas de la tierra, porque la tierra del padre es la esencia de la herencia y, en particular, lo es la tumba del padre, que habrá de pisar antes de ejecutar el plan de venganza, por expresa recomendación del oráculo. Ella

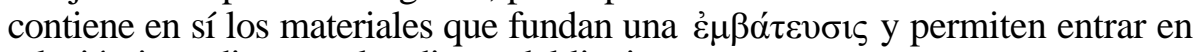
relación inmediata con los dioses del linaje paterno.

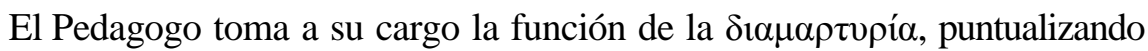
tanto su estatus social de salvador y educador, como su rol de testigo del exilio del príncipe. En el momento de la toma de posesión, el sucesor está, 
normalmente, asistido por los suyos, por el grupo de parientes más próximo. Aunque Orestes no será investido por ellos, la autoridad del Pedagogo es suficiente pues emana de su capacidad de dar testimonio del espacio geográfico de la tierra patria y de la historia personal del hijo del Atrida. Tras encadenar los hitos cruciales de su vida conforme al relato mítico tradicional, se dirige a Orestes por primera vez, no como su discípulo, sino como el

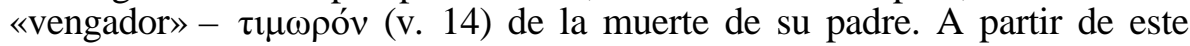
momento Orestes debe hacerse cargo de la concreción de la venganza.

Encuadradas en ese espacio cualificado aparecen las dos imágenes que el ayo posee del sucesor. Una pertenece al pasado y nos muestra a Orestes en un papel pasivo (v.11-13), enfatizando la misión de su protector con la primera persona como ejecutor de la acción salvadora que le fuera encomendada por la hermana: «de donde en otro tiempo te saqué después del asesinato de tu padre, habiéndote recibido de manos de tu hermana, la

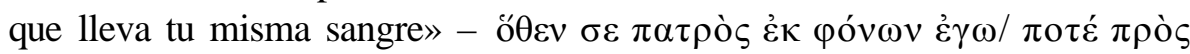

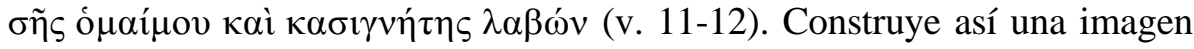
de Orestes niño, inconsciente de su destino, alejado de las desgracias de su familia y muestra cómo su coraje permitió su salvación e implicó, luego, su crianza hasta su juventud. La otra imagen lo ubica en el presente cuando ya el papel de Orestes debe tornarse relevante: «... hasta tanto llegaras a la edad de ser vengador de la muerte de tu padre. Y ahora, ciertamente, Orestes y tú Pílades, el más querido de los húespedes, debéis tomar pronto

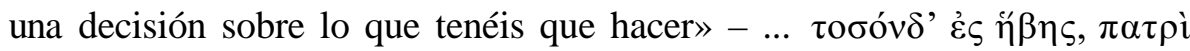

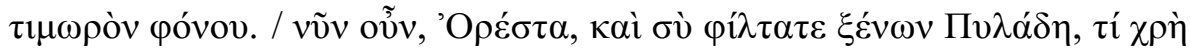

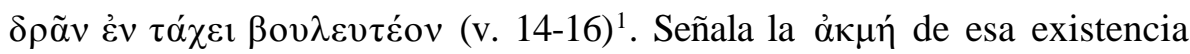
destinada perentoriamente al deber de la venganza. El Orestes que regresa es su discípulo con lucidez y plena conciencia de lo que hay que hacer. El Pedagogo se relega a un segundo término, el del hombre fiel, dispuesto a ayudar y a esclarecer las dificultades. Deja en manos de Orestes las decisiones, porque la llegada al hogar simboliza para el joven el logro de la madurez necesaria para cumplir su misión. Orestes se ha afirmado como individuo, como sujeto de derecho, comprometido en una acción que tiene como objetivo recuperar el centro del poder familiar cuyo eje es el culto a los muertos y, por lo tanto, el cumplimiento de las prácticas tradicionalmente obligatorias, $-\tau \alpha$ vó $\mu \mu \alpha \alpha-$, que al ser violadas por un delito de homicidio deben

1 Las citas del texto en griego están tomadas de la edición de Sir Richard C. Jebb, The Electra of Sophocles. Cambridge, 1967. Las citas en español están tomadas de la traducción de Assela Alamillo, Madrid, 1981. 
ser vengadas por los parientes hasta el tercer grado, los mismos que forman parte de la estrecha comunidad del culto, aquellos que tienen derecho a heredar al muerto y a quienes incumbe, a la par, el deber de rendir culto a su alma.

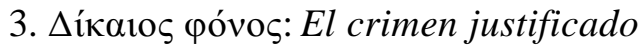

Con la $\tilde{\rho} \tilde{\sigma} \lessdot \varsigma$ de Orestes se inicia el drama de la venganza, difícil y peligrosa, cuyo protagonista es el hijo varón que debe matar a su madre por designio de los dioses. Apolo se lo ha ordenado; sin embargo, en ningún momento a lo largo de este discurso Orestes la nombra , como si quisiera olvidar el horrible crimen que significa hundir la espada en el seno de una madre. No hay otro que pueda ofender más a los dioses y a los hombres; no

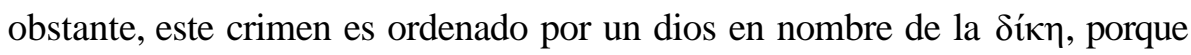
el hijo debe vengar al padre y porque el único derecho que permite el castigo de Clitemnestra es este derecho familiar. En nombre de él la llegada de las divinidades vengadoras, las Erinnias, será anunciada por el coro en la antiestrofa del primer estásimo, precedidas por «la Justicia, llevando en sus manos justos poderes» (v.475). Estas diosas, que desempeñan un papel tan importante en Esquilo y Eurípides, no aparecen en esta tragedia para atormentar a Orestes sino para castigar «una unión manchada de sangre» (v. 491). La solidaridad religiosa de la familia cobra tal relevancia que la herencia fatal del crimen, sin ser negada expresamente, pues también el coro alude a ella en el épodo de este canto, ya no es puesta en escena. Parecería que Sófocles ha encontrado para este tema un nuevo punto de tensión entre la antigua concepción religiosa de la falta, que persigue al individuo de generación en generación, y la concepción nueva, respaldada por nuevos dioses - Zeus y Apolo -, que ilumina las prácticas procesales de la Atenas del siglo V. «Tensión que», como explican Vernant y Vidal-Naquet 1987, p. 38 , «se produce entre el mito y las formas de pensamiento propias de la ciudad, conflictos en el hombre, el mundo de los valores, el universo de los dioses, carácter ambiguo y equívoco de la lengua, todos estos son los rasgos que marcan fuertemente la tragedia griega. Pero lo que quizá la defina de modo esencial es que el drama llevado a la escena se desarrolla a la vez en el plano de la existencia cotidiana, en un tiempo humano, opaco, hecho de presentes sucesivos y limitados, y en un más allá de la vida terrestre, en un tiempo divino, omnipresente, que abarca en un instante la totalidad de los su- 
cesos, unas veces para ocultarlos, otras para descubrirlos, pero sin que jamás se le escape nada, ni se pierda nada en el olvido. Por esta unión y confrontación constantes, a lo largo de la intriga, del tiempo de los hombres y del de los dioses, el drama aporta la revelación manifiesta de lo divino en el curso mismo de las acciones humanas». Es así como en la perspectiva trágica de la Atenas de Sófocles aún se mantenía en pleno vigor la creencia de que el alma de una persona muerta por la violencia vagaba sin encontrar sosiego mientras no se vengase el crimen en el asesino, encolerizada por el delito de que había sido víctima y enfurecida contra los llamados a vengarla que no cumplían con su deber.

Si bien el estado prohibía a los parientes tomar la justicia por su mano, los incitaba, a cambio de ello, a llevar al agresor ante los tribunales y luego, el propio estado se encargaba de pronunciar la sentencia y de ejecutarla, si fuere condenatoria, aplicando el correspondiente castigo. Mediante trámites procesales minuciosamente establecidos los tribunales competentes en cada caso decidían si la acción debía ser considerada como un 'asesinato pre-

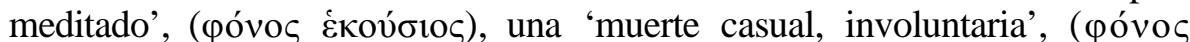

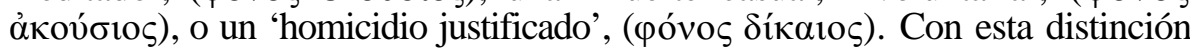
el estado introdujo una reforma a fondo del antiguo régimen de la venganza de la sangre en el que el derecho a vengar se ponía exclusivamente en manos de la familia y en el que el asesino era, sin más, reo de la pena de muerte. Sin embargo, el estado no hace sino tomar a su cargo los derechos y exigencias de caracter religioso pues seguía viendo el delito de homicidio como una mancha que caía sobre el culpable y amenazaba caer sobre toda la ciudad. No podía ser, por lo tanto, reclamado por cualquier ciudadano por medio de una $\gamma \rho \alpha \varphi \eta ́$, sino por los parientes próximos del muerto en el marco de la $\delta$ í $\eta$, que al tomar como eje del culto familiar el culto a los muertos gira en torno a la noción de vó $\mu \mu \alpha$ que engloba todos los ritos tradicionalmente obligatorios. Cuando éstos han sido violados por un delito de homicidio cometido en el seno de una misma familia, los procedimientos para vengarlo se tornan complejos y recaen sobre un tribunal de fundamentos claramente religiosos, presidido por el arconte-rey, la Boulé del Aréopago, el más alto tribunal de sangre que funcionaba en Atenas. Bajo su jurisdicción se hallaban

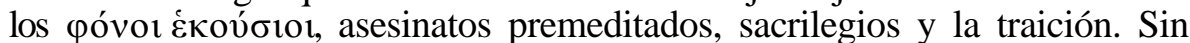
embargo, de los actos de Clitemnestra nada se dice acerca de que hayan sido sometidos al juicio de ningún tribunal y serán sus propios hijos los portavoces de la posición conservadora que Sófocles sostiene en lo que, seguramente, era un acuciante debate en la sociedad ateniense de su época.

En el tratamiento dado a este tema por Sófocles, se destaca el profundo cambio operado en cuanto a la fe en el alma en los tiempos posteriores a Homero. Ahora el dios délfico ejercía también su tutela sobre los derechos 
de los muertos, y el hecho de que sus oráculos confirmasen la santidad del culto del alma tenía, por fuerza, que contribuir a hacer valer este culto. Las normas de Delfos alcanzaban una influencia aún más profunda cuando se trataba de una persona muerta violentamente y sus sacerdotes eran la cofradía sacerdotal a quien los estados griegos conferían la máxima autoridad en la reanimación y desarrollo del proceso judicial que penalizaba estos crímenes.El alma de Agamenón depende, naturalmente, del culto que le tributen los miembros de su familia que aún viven y su suerte se halla determinada por el deber piadoso de la venganza. Esta fe difiere totalmente de la concepción expresada en los poemas de Homero, que muestra a las almas desterradas en el reino de Hades eternamente sustraídas a los cuidados y deberes de los vivos. En cambio, en la obra de los trágicos advertimos que el castigo o la recompensa que las almas de los muertos encuentran en la vida no depende de sus propios méritos, ni de su naturaleza heroica, ni de la conducta que siguiera en vida, sino de la que los supervivientes sigan con respecto a ella. A la luz de estas ideas está elaborada, no sólo la $\rho \tilde{\eta} \sigma ı \varsigma$ de Orestes, sino todo el drama de Electra.

En este primer discurso de Orestes se pueden esclarecer estos rasgos indudables del antiguo deber impuesto por la venganza de la sangre, modificados a tono con las exigencias del mandato de Apolo. La interpretación que el príncipe hace del oráculo trae consigo, por sí misma, la liberación del castigo de las Erinnias y el encuadre de los nuevos crímenes como un bien

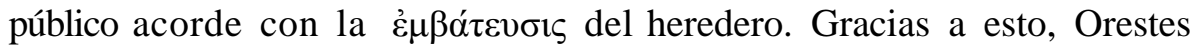
puede afirmar al cerrar la tragedia: «Sería preciso que esta justicia fuese inmediata para el que quisiera transgredir las leyes: la muerte. Así el malvado no abundaría tanto» (v. 1505).

La estrategia preponderante de esta $\dot{\rho} \tilde{\eta} \sigma ı \zeta$ es exponer el plan de

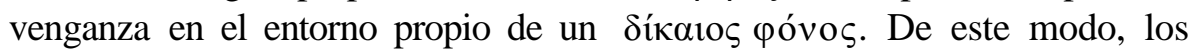
nuevos asesinatos se encuadran en la categoría del 'crimen justificado'. La sombra de un juicio humano ante el tribunal del Delfinión, al que conduciría tal situación en el siglo $\mathrm{V}$, no agobia al joven, porque su misión de "vengador" se halla inmersa en un espacio consagrado, el santuario de Apolo en Delfos y posee el respaldo de una palabra trascendente, la profecía del dios. Al ser el oráculo el que le ordena el asesinato deliberado de su madre no hay resquicio para la vacilación humana ni para la intención delictiva del sujeto. Decisión y responsabilidad son los ejes que modalizan la exposición del plan.Ambas proceden del derecho antiguo, jamás derogado desde que Dracón le diera forma legal, según el cual, los más próximos parientes del muerto se hallaban exclusivamente autorizados, a la par que irremisiblemente 
obligados, a perseguir judicialmente al asesino. Quedan los dioses y los hombres en su individualidad absoluta sin verse inmersos en el clima de ambigüedad que tiñe el juicio de Orestes en Euménides de Esquilo.

La audiencia preliminar - que en Atenas realizaría el arconte, antes de que el caso llegara a los tribunales -, podría situarse en la visita al santuario de Delfos. Tras ella, Orestes se muestra como un individuo capaz de elegir deliberadamente el mejor modo de ejecutar el mandato del oráculo. Su relato crea una atmósfera de interrogación y esclarecimiento de la verdad que forma parte de su proceso de maduración, a fin de que pueda establecer su

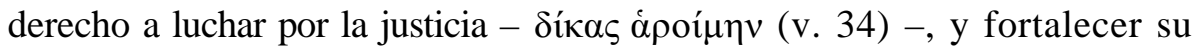
identidad de vengador. Al asumirla ya no dudará acerca del encuadre de su

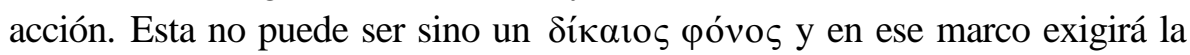

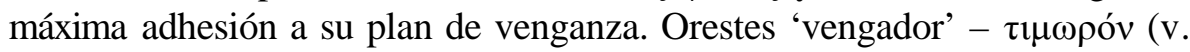
14) -, adhiere íntimamente a la voluntad de Apolo y se presenta él mismo

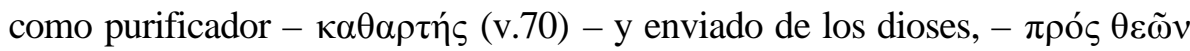
$\grave{\omega} \rho \eta \mu \varepsilon ́ v o \varsigma$ (v.70) -, implorando la ayuda de los dioses patrios para no ser expulsado de su tierra sin honra. Está atrapado, y de antemano lo sabe, entre dos exigencias de lo divino: matar y sufrir el castigo por haberlo hecho. Parece una trampa sin salida para una conciencia recta, puesto que el mundo de los dioses, al que es forzoso obedecer, es el que está aparentemente dividido: «Por qué ha de inquietarme esto cuando, muerto de palabra, estoy de hecho vivo y voy a obtener fama con ello?» (vv. 59-60)

La ỏvókpıбıৎ como audiencia de interrogación y esclarecimiento de la

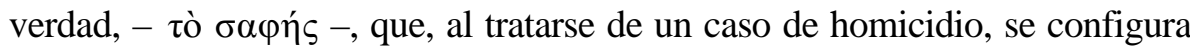
como una $\pi \rho \circ \delta \iota \kappa \alpha \sigma i ́ \alpha$, se podría advertir en el relato de la consulta al oráculo. Orestes la ha realizado con el propósito de adquirir la seguridad necesaria, no para descubrir a los culpables, que todos conocen bien, sino para

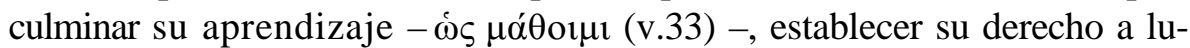

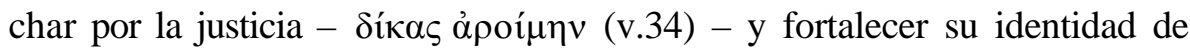
vengador, garantizando que lo que habrá de exigir luego a sus más íntimos amigos, es lo correcto. Su principal móvil en la visita a Delfos parece haber

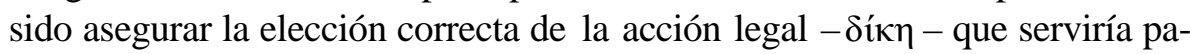
ra cumplir con su deber: «de qué modo vengaría a mi padre de sus asesinos»,

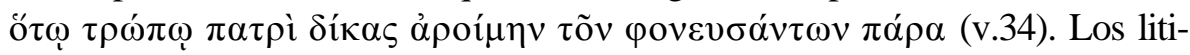

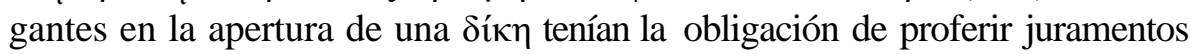
sobre la veracidad de su pedido y ser respaldados por varios miembros de su familia en una especie de promesa colectiva, bajo el nombre de $\delta \omega \mu$ бí $\alpha$. 
Aún hay huellas de tal conjuración en la legislación de Dracón que constituye una especie de hito, pues revela una cierta exigencia de la prueba para perseguir y condenar a un acusado. Si bien Orestes no recurre a un juramento para hacer valer sus derechos de vengador ha consultado el oráculo pítico, que lo confirma como tal. Asume este deber absoluto, - deber de conciencia, privado, reivindicación imperiosa del difunto -, como su condición existencial y hace de Apolo el testigo fundamental de la verdad de su palabra. La decisión de Orestes se deja oir con el tono de una revelación - $\tau \grave{\alpha}$ $\delta o ́ \xi \alpha v \tau \alpha \delta \eta \lambda \omega ́ \sigma \omega$ (v.29) -, que ha sido iluminada por el dios profeta. La cita textual de la respuesta de Febo y la necesidad ineludible, con que la introduce, autentifican sus futuras órdenes y la búsqueda de esa adhesión o diwmosía que exige a sus acompañantes: «me responde Febo lo que al punto conocerás: que yo mismo, desprovisto de escudo y ejército, con

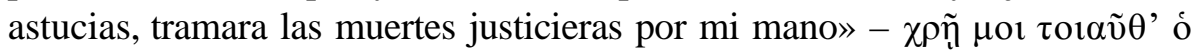
Фoĩßo

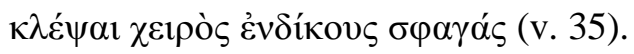

La palabra del príncipe se manifiesta como la sentencia de Apolo: $\lambda o ́ \gamma \omega$ $\delta \varepsilon \grave{\varepsilon} \chi \rho \tilde{\omega} \tau o i \tilde{\omega} \delta$ ' (v. 44). Presenta así como irrefutable la estrategia urdida y se coloca explícitamente como fuente evaluativa de la orden que emite: «Anuncia, reforzándolo con un juramento, que ha muerto Orestes debido a

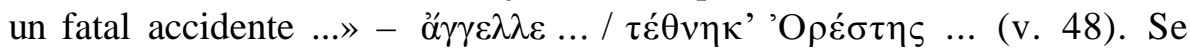
instaura como sujeto de la cláusula subordinada y crea una distancia enunciativa que sirve para enfatizar la seguridad que deposita en su interpretación del oráculo. Lo que presiente como factible de corrección (v.31) lo muestra, luego, como infalible (vv.51-58). Mediante este efecto de objetivación sus interlocutores no tendrán ya ningún derecho a impugnar su plan.

La diamarturía del pedagogo respecto de su calidad de heredero y vengador queda así respaldada por la autoridad del dios, que lo avala para

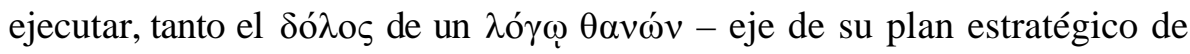
penetración en el palacio -, como el asesinato de Egisto y el matricidio, sin la mancha que procedería de una decisión humana. De este modo pasa a primer plano lo que es secundario: la intriga previa a la ejecución de la venganza, que es el proyecto con que Orestes interpreta el objeto de la consulta al oráculo, - el modo de llevar a cabo la venganza -, el ö $\tau \tau_{\uparrow} \tau \rho o ́ \pi \omega$

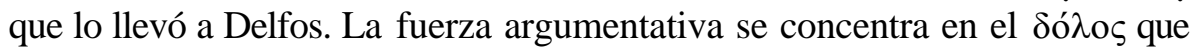
se despliega en círculos concéntricos como un permanente $\lambda$ ó $\gamma$ os, una fic- 


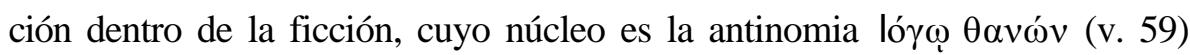

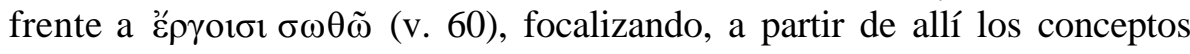
ventajosos que proceden del éxito de su decisión se suceden uno tras otro:

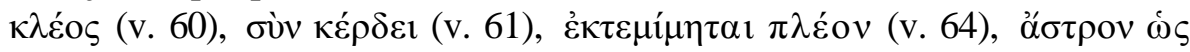

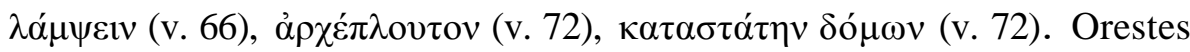

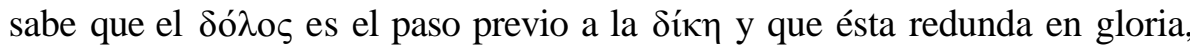
para los hombres y para los dioses: «Así también yo me jacto de que, como resultado de esta noticia, brillaré vivo entre mis enemigos como una estrella» (vv. 65-66).

También era el oráculo de Delfos el encargado de velar por la ejecución de los actos expiatorios y purificadores. La necesidad de cumplir esta clase de actos procedía de la leyenda de la fuga y purificación del propio Apolo después de haber dado muerte en Pito al espíritu de la tierra. Y es también en Delfos donde, según el poema de Esquilo, cuida el propio Apolo de purificar a Orestes de su matricidio. A pesar de que los ritos expiatorios no son privativos del culto apolíneo - hállanse consagrados también a otros dioses, ctónicos en su mayoría -, es el oráculo délfico quien confirma su santidad.

Las ideas que afloran en la plegaria de Orestes (v.67-72) adquieren mayor fuerza, precisamente, porque el oráculo del dios omnisciente santifica y aconseja la expiación de los delitos de sangre, a la par que el estado reglamenta, en base a la antigua venganza familiar de la sangre, la persecución de los asesinatos.

Como manifestación de su religiosidad la plegaria abre un nuevo diálogo entre Orestes y sus dioses tutelares, entre el heredero y esa fuerzas que emanan de la tierra de sus ancestros y de la casa paterna. Presupone una fe firme en su poder y en su benevolencia, además del reconocimiento tácito de su inferioridad frente a ellos, y la amistosa confidencia de sus más íntimos anhelos. Estas ideas descansan sobre esa relación establecida entre la religión y el estado y hacen explícita la vinculación de esta oración de Orestes y su $\grave{\varepsilon} \mu \beta \alpha ́ \tau \varepsilon v \sigma i \varsigma$, a partir de la convicción de que el alma de Agamenón sigue viviendo dotada de conciencia y habita esos poderes invisibles, y que, gracias a ello, conoce lo que pasa en el mundo de los vivos. Las almas de los padres de generaciones anteriores son dioses familiares y en esta creencia se halla la raíz de todo el culto del alma como la fuente más remota de la religión. Esta fe se conservó sin abandonar las viejas tradiciones, a la sombra de los grandes dioses olímpicos y de su culto, en medio del paulatino despliegue del poder y las instituciones del estado. 


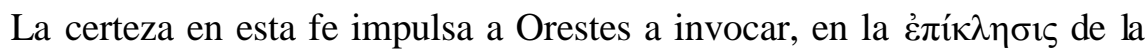
plegaria, a sus dioses familiares y a su tierra, como testigos de su reentronización, a fin de que ésta tenga éxito y su condición de sucesor alcance la

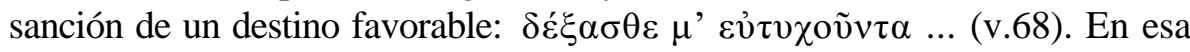
relación personal que los une radica la idea de retribución y representación del orden moral de acuerdo con el cual se realiza la retribución.

En segundo lugar, después de la invocación a los dioses y a la tierra patria, Orestes toma como destinatario de su súplica al palacio: la «morada llena de horrores» (v.10) que le mostrara el pedagogo requiere una purificación. Es el mismo Orestes quien asume la función propia del dios de Delfos, presentándose con el más alto título personal que le confiere el máximo de-

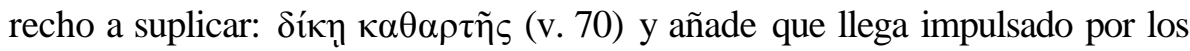

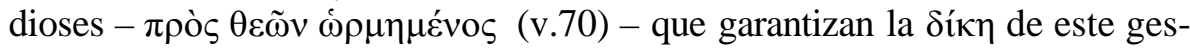
to.

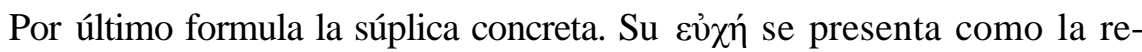
clamación de un derecho natural: el derecho a recuperar su heredad. Esta

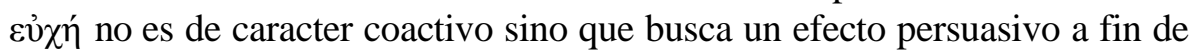
no ser víctima de la ỏ $\tau \mu$ ía que supone la pena del destierro como justa componenda en los conflictos de sangre.

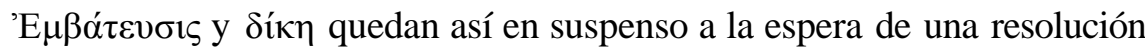
favorable tras el cumplimiento de la venganza.

Resta ahora llevar a cabo los ritos en la tumba de Agamenón. Será Crisótemis quien dé a conocer estos hechos en el segundo episodio sin atisbos de duda acerca de la presencia de su hermano (v. 909ss). En Las Coéforas de Esquilo, en cambio es Electra, que esperaba angustiada su regreso, quien reconoce sobre la tumba signos que no le permiten dudar de que su hermano ha regresado (v. 172). Eurípides también reelabora estos ritos en su Electra, presentándolos con rasgos de cierto humor (v. 899ss). Es interesante destacar que estos datos del mito se remontan hasta la versión de Estesícoro quien los elaboró literariariamente en el siglo VII a C. Aparece frente a tal situación una especie de postulado que es compartido por los tres trágicos: sólo Orestes ha podido llegar hasta la tumba de su padre de la manera que se nos describe. Sólo él estaba autorizado a poner el pie en lo alto del túmulo y realizar el rito de la ofrenda del rizo que establece un vínculo religioso entre el heredero varón y su progenitor. Orestes está obligado a reconocer su dependencia de los dioses familiares y del alma de sus antepasados, con estas muestras de un culto que comprende tanto su plegaria como la ofrenda, 


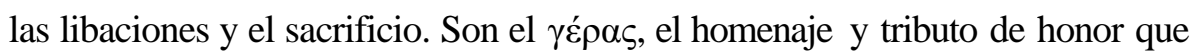
corresponde recibir a las almas por derecho propio.

\section{A modo de conclusión}

Para comprender en todo su alcance las ceremonias y prácticas externas en que se manifiestan los rasgos entrevistos de la legislación ateniense, con respecto a los derechos de sucesión y en relación con la venganza de la sangre, hubiera sido necesario seguir observando sus apariciones en toda esta tragedia. El análisis del Prólogo no es más que una muestra, suficiente creemos, para comprobar cómo los dos discursos confluyen a demostrar que el oráculo de Apolo, como dios profeta de Zeus, trae consigo un efecto de indulgencia y persuasión, que se suma a la súplica de Orestes a los dioses y el palacio paterno, a fin de confirmar que la venganza del asesinato de

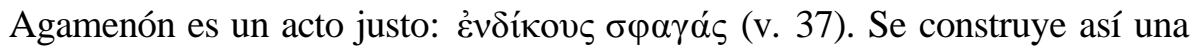
imagen del delito real, - asesinato de Egisto y matricidio -, como el lugar de una verdad exterior al sujeto-agente, Orestes, que posee la fuerza sagrada de la ley divina.

Con esto queda asegurada la complicidad de los conjuradores, el pedagogo y Pílades, que comparten con Orestes un mismo paradigma de conocimientos del mundo: su adhesión silenciosa presupone la existencia de ciertas instituciones humanas que regulan su conducta.

La jerarquía política de Orestes como sucesor de Agamenón, una vez garantizada por el Pedagogo, y sobre todo por Apolo, le permite producir un discurso cuyo tono de mandato se inscribe en una relación interpersonal de máxima confianza y solidaridad que garantizan su cumplimiento. Inmerso en este contexto el imperativo de la venganza se torna un llamado al aỉós, hacia las obligaciones que todo hombre tiene para consigo mismo y con los

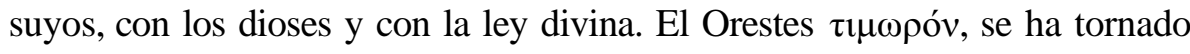

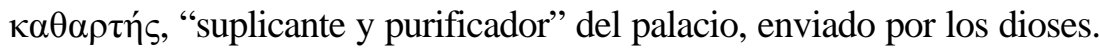

